\title{
Influence of mental practice and movement observation on motor memory, cognitive function and motor performance in the elderly
}

\author{
Caroline D. C. Altermann ${ }^{1}$, Alexandre S. Martins ${ }^{1}$, Felipe P. Carpes ${ }^{2}$, \\ Pâmela B. Mello-Carpes ${ }^{1}$
}

\begin{abstract}
Background: With aging, it is important to maintain cognitive and motor functions to ensure autonomy and quality of life. During the acquisition of motor skills, it is necessary for the elderly to understand the purpose of the proposed activities. Physical and mental practice, as well as demonstrations, are strategies used to learn movements. Objectives: To investigate the influence of mental practice and the observation of movement on motor memory and to understand the relationship between cognitive function and motor performance in the execution of a sequence of digital movements in the elderly. Method: This was a cross-sectional study conducted with 45 young and 45 aged subjects. The instruments used were Mini-Mental State Examination (MMSE), Manual Preference Inventory and a Digital Motor Task (composed of a training of a sequence of movements, an interval and a test phase). The subjects were divided into three subgroups: control, mental practice and observation of movement. Results: The elderly depend more strongly on mental practice for the acquisition of a motor memory. In comparing the performances of people in different age groups, we found that in the elderly, there was a negative correlation between the MMSE score and the execution time as well as the number of errors in the motor task. Conclusions: For the elderly, mental practice can advantage motor performance. Also, there is a significant relationship between cognitive function, learning and the execution of new motor skills.
\end{abstract}

Keywords: cognition; motor memory; movement; aging; rehabilitation.

\section{HOW TO CITE THIS ARTICLE}

Altermann CDC, Martins AS, Carpes FP, Mello-Carpes PB. Influence of mental practice and movement observation on motor memory, cognitive function and motor performance in the elderly. Braz J Phys Ther. 2014 Mar-Apr; 18(2):201-209. http://dx.doi. org/10.1590/S1413-35552012005000150

\section{Introduction}

Given an increase in life expectancy, the elderly population has grown dramatically worldwide in recent decades. This increase must be associated with the development of new strategies and clinical research. An increasing number of studies have focused on public health issues related to aging, showing an increase in the number of elderly people in society and the search for an improved quality of life of these individuals ${ }^{1,2}$.

Human aging is accompanied by structural and neurophysiological changes in the central nervous system and varying degrees of cognitive decline ${ }^{3}$. Studies suggest that the elderly exhibit a decrease in learning, memory, attention, executive functions and sensorimotor performance, even when not afflicted with diseases ${ }^{4-6}$. The most widely studied cognitive function in the aging process is memory ${ }^{7-10}$. Several processes need to occur for memory formation, including the acquisition, consolidation, retention and retrieval of information ${ }^{11}$.

Motor memory is a procedural memory, and the learning of a motor skill represents the acquisition and consolidation of a sequence of complex movements, such as those involved in learning to weave or ride a bicycle. In addition, learning new motor skills is a fundamental adaptation mechanism in humans and animals ${ }^{12}$. The elderly become slower at learning new motor skills than young adults because they differ from young individuals in terms of cognitive processing speed, not in the ability to learn new motor skills $^{13}$. In motor skill acquisition, demonstration of the movement and verbal instructions, as well as

\footnotetext{
${ }^{1}$ Stress, Memory and Behavior Laboratory, Universidade Federal do Pampa (UNIPAMPA), Uruguaiana, RS, Brazil ${ }^{2}$ Laboratory of Applied neuromechanical, Universidade Federal do Pampa (UNIPAMPA), Uruguaiana, RS, Brazil Received: 07/19/2013 Revised: 10/07/2013 Accepted: 10/15/2013
} 
physical and mental practice, seem to act together and in a complementary manner to facilitate learning ${ }^{14,15}$.

Demonstration is useful in learning a skill because it reduces uncertainty about how the motor activity should be performed ${ }^{16}$. Moreover, demonstration is an important source of information in the learning process, and it consists of providing a representative image of the task to be performed ${ }^{17}$. The practice can be divided into two different types, physical and mental, with the physical practice being characterized by motor execution of a given task/movement so that, after a period of practice, the task can be performed more easily. Thus, physical practice can contribute to the improvement or maintenance of the level of motor coordination and delay the effects of aging on the performance of the skill ${ }^{18}$. In turn, mental practice, or movement planning, is defined as a cognitive rehearsal of a physical skill in the absence of explicit physical movements ${ }^{19}$. Mental practice can be used to facilitate the learning and improvement of skills or sequences of skills ${ }^{15}$ because approximately the same neural network in the sensory-motor system is activated when an individual imagines or performs an motor action ${ }^{20}$.

In the elderly, the maintenance of cognitive and motor functions is one of the main challenges in maintaining quality of life. Thus, for multiple strategies for the treatment/training of motor functions to be effective, there is a need for good cognitive function. The elderly should be able to understand the purpose of the proposed activities, as well as the instructions received. Thus, understanding the learning abilities of the elderly allows the determination of the best intervention method for motor tasks ${ }^{21}$. There is still controversy regarding the decline of the learning ability throughout aging, as well as the impact of interventions during this process. Therefore, the present study aimed to investigate the influence of mental practice and movement observation on motor memory, as well as the relationship between cognitive function and motor performance in the execution of a sequence of digital movements in the elderly.

\section{Method}

\section{Participants}

Young adults and elderly individuals were selected to participate in the study. The elderly individuals were recruited from a social group, and they were autonomous, socially active and involved in physical, social and cognitive activities at least three times per week. These activities included walking, stretching, outdoor gym exercises, Tai Chi Chuan, memory games, chess, card games and group reading. Young adults ranged from 18 to 30 years of age. Selfclassified as healthy and active regarding the practice of daily activities. Neither group included subjects who practiced physical exercise regularly. To be included in the study, the participants could not have orthopedic diseases or injuries of the upper limbs or, in the case of the elderly, cognitive impairment consistent with dementia.

The study group consisted of 45 young adults and 45 elderly individuals of both genders. The educational level was considered for the final analysis of the results related to the evaluation of cognitive function using the Mini-Mental State Examination $(\mathrm{MMSE})^{22}$. The characteristics of the participants are shown in Table 1. All procedures developed in this study were approved by the Research Ethics Committee of the Universidade Federal do Pampa (UNIPAMPA), Uruguaiana, RS, Brazil, under protocol $n^{\circ} 101.557$, from 2012. Each participant was informed of the objectives and procedures of the study and signed an informed consent form.

\section{Procedures}

The study procedures involved the application of the following instruments, in order of presentation:

- Socio-demographic form: This form was used to collect data for defining the participants profile, including gender, age, marital status, education level and the presence of chronic diseases;

- Mini-Mental State Examination (MMSE): This test was used to determine the general cognitive function and to identify any undiagnosed cognitive deficit. The MMSE is divided into five sections (orientation, immediate memory, attention and calculation, recall and language ${ }^{22}$ ) and provides evidence for presence of dementia. The participants who obtained scores below the minimum value for their level of education, according to the classification proposed by Brucki et al. ${ }^{23}$, were excluded from the analysis of the results;

- Edinburgh Handedness Inventory (EHI): This tool was used to determine the handedness of subjects ${ }^{24}$, which served as a parameter to select the hand to be used in the subsequent task;

- Motor task - execution of a sequence of digital movements: The participants were subjected to 
training, which was followed by an interval and subsequent testing of a sequence of five digital movements with the non-dominant hand (adapted from Ungerleider et al. ${ }^{25}$ ). The sequence involved the movement of the following fingers: 4, 1, 3, 2, 4 , according to the numbering shown in Figure 1.

The thumb was not used to perform the sequence.

This task involved a training phase in which the participants practiced the sequence of movements ten times with the non-dominant hand (left/right). This phase was followed by an interval phase of approximately 2 minutes, during which, depending on the subgroup, the subjects did not perform any task-related activity (control subgroup), observed the execution of the sequence of movements by one of the trained researchers (observation subgroup) or mentally practiced the movements learned during the training phase (movement planning subgroup). Finally, there was a test phase in which the subjects repeated the sequence of movements ten times, as fast and as accurately as possible ${ }^{25,26}$. The execution of the motor task was videotaped for later analysis. The time required for the execution of the movements during the training and testing phases as well as the number of execution errors were recorded.

\section{Statistical analysis}

To assess the normality of the data, the ShapiroWilk test was used. To compare the performances of each of the six subgroups during the training and test phases of the motor task, the Wilcoxon test for dependent samples (variable execution time) and Student's $t$-test for dependent samples (variable number of errors) were used. The Kruskall-Wallis test followed by Dunn's post hoc test(variable execution time) and one-way ANOVA followed by a Bonferroni post-hoc test (variable number of errors) were used to compare the performances of different groups/subgroups in the motor task test. The MannWhitney (variable execution time, difference between

Table 1. Age, gender and education levels of the subjects.

\begin{tabular}{ccc}
\hline Characteristic & $\begin{array}{c}\text { Young } \\
\mathbf{n = 4 5}\end{array}$ & $\begin{array}{c}\text { Elderly } \\
\mathbf{n = 4 5}\end{array}$ \\
Age in years & 22.28 & 73.04 \\
$( \pm 2.97)$ & $( \pm 6.82)$ \\
(mean and standard deviation) & $14 / 31$ & $9 / 36$ \\
Gender (M/F) & $0 / 45$ & $1 / 44$ \\
Education (illiterate/literate) & 13.22 & 7.32 \\
Education in years & $( \pm 1.24)$ & $( \pm 4.75)$ \\
\hline (mean and standard deviation)
\end{tabular}

training and test time and MMSE) and Student's $t$-test for independent samples (variable number of errors) were used to compare the performances on the motor task test and the cognitive functions between young adults and the elderly. The Spearman test (MMSE score $\mathrm{x}$ execution time; MMSE score $\mathrm{x}$ execution error) was used to verify the correlation between cognitive function and motor performance in the execution of movements. In all analyses, results were considered significant when $P \leq 0.05$.

\section{Results}

The overall mean MMSE score in the young adult group was $28.26 \pm 2.64$, while that in the elderly group was $25.64 \pm 3.08$, resulting in a significant difference in the cognitive function of individuals of different ages $(P<0.0001$ by the Mann-Whitney test). There were no differences between the scores of the subgroups of each age group.

When comparing the times required to perform the motor task during training and testing, young adults showed improvement in the execution time in all subgroups evaluated (Figure $2 \mathrm{~A}, P<0.001$ ). For

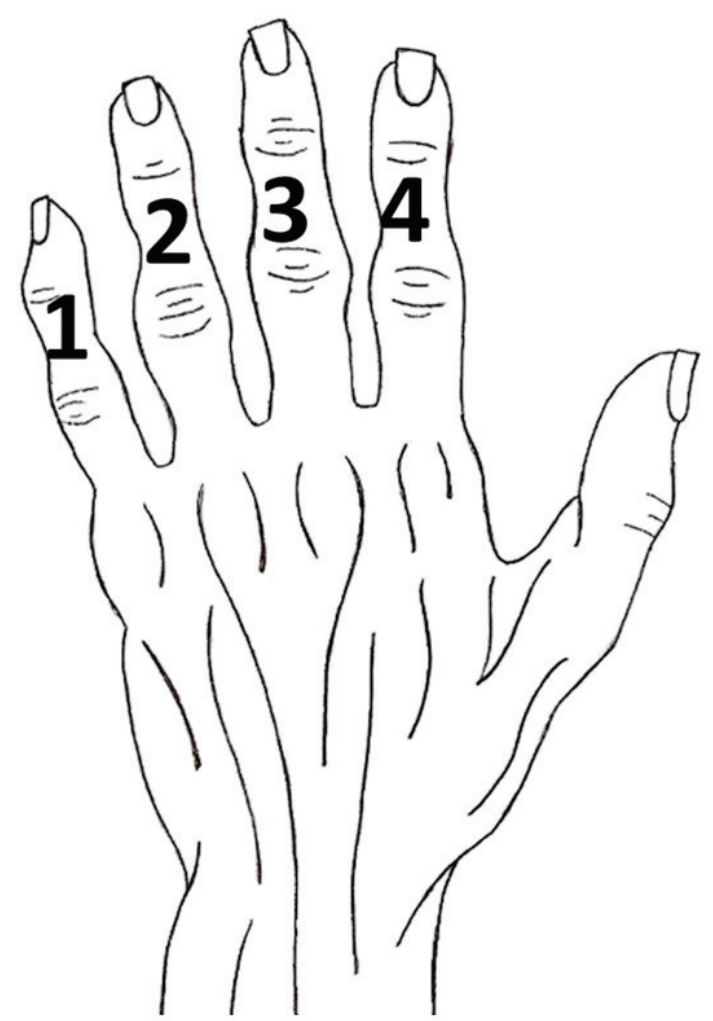

Figure 1. Identification of the fingers used to perform the sequence of movements in the digital motor task. 
the elderly, there was improvement in all subgroups; however, the subgroup that conducted movement planning showed a more significant difference between the execution times in the training and test phases $(P<0.01)$ than the other elderly groups (Figure $2 \mathrm{~B} ; P<0.05$ ), with this group showing a significantly greater reduction in the execution time of the task than all the other groups (Figure 3A, difference in training and test times, $\mathrm{P}<0.05)$. No significant differences were observed in the numbers of errors when comparing the training and test phases (Figure 2C and 2D) between subgroups.

We observed no differences in the execution times (Figures 2A and 2B, test) or the numbers of execution errors (Figures 2C and 2D, test) among the different subgroups of each age group.

When comparing the performances of the subgroups (control, observation and movement planning - young adults x elderly), a difference in the variation of the time required for task execution between the training and test phases was observed (Figure 3A). In the observation $(P<0.05)$ and planning $(P<0.01)$ groups, the execution time decreased significantly more for the elderly than for the young adults. There was also a difference between the age groups in the execution time of the motor task (Figure 3B; $P<0.01$ for the control and observation groups, $P<0.01$ for the planning group) but not in the number of errors (Figure 3C).

Among the elderly, there was a negative correlation between the MMSE score (cognitive performance) and the number of errors in the motor task execution during the test phase (Figure 4A; $\rho=-0.470$; $P=0.001)$ as well as between the MMSE score and the execution time (Figure $4 C ; \rho=-0.354 ; P=0.016$ ). In the young adults, the MMSE results did not correlate with the number of errors (Figure $4 B, \rho=-0.106$; $\mathrm{P}=0.485$ ) or execution time (Figure $4 \mathrm{D} ; \rho=-0.015$; $P=0.917)$.

\section{- Discussion}

The present study assessed the influence of mental practice and movement observation on the motor learning and memory in young adults and elderly, as well as the relationship between cognitive function and motor performance in the execution of a sequence of digital movements.

Our results demonstrate that cognitive performance, as assessed by the MMSE and following the cutoff points proposed by Brucki et al. ${ }^{23}$, although different when comparing the groups, is within the expected values for both the young adults and the elderly.
Thus, the sample exhibits a good overall cognitive level even among the elderly, in spite of aging commonly being associated with a reduction in cognitive functions related to information processing. The processes of executive function, attention and memory are especially affected with age, as well as learning aspects, the process of selection and the programming of motor response ${ }^{27-29}$. Most likely, the fact that these functions are preserved is related to the practice of physical, social and cognitive activities by the elderly.

When analyzing the performance during training and testing, especially in relation to the execution time of the motor task, a difference between the two phases was observed. With repetition during training, a shorter time was required for the task in all groups. During training, it is essential to make the observer realize the important aspects of the action to form a reference for later reproducing the movements accurately. In the review by Tani et al. ${ }^{17}$, the authors reported that one way to ensure learning is through demonstrating a task multiple times, which favors an increase in the selectivity of information for movement production and error correction.

The amount of time required to perform the motor task was greater for the elderly than for the young adults, both during the training and test phases. This result may be related to the fact that aging involves a variety of factors that result in functional loss, such as decreased cerebral blood flow, gray matter and brain volume ${ }^{30}$. It also involves a longer reaction time and slower movement ${ }^{31}$. All these nonpathological changes can affect the cognitive and motor performance of the elderly because executive functions play an important role in learning ability and motor performance ${ }^{32}$. This result corroborates the study of Toledo and Barela ${ }^{33}$, who observed differences in sensory and motor performance between young and elderly individuals in learning/ performing a new task, with the elderly showing poorer performance.

Diniz et al..$^{34}$ studied children, adults and elderly individuals during the learning of a serial task, which consisted of touching sensors with the index finger of the dominant hand, six times in response to light stimuli. The authors observed that adults had better responses than children and elderly, and only adults were able to learn the full sequence of the serial pattern. The elderly group showed better performance than the children at the beginning of the practice, which could be explained by the motor experience acquired throughout their lifetimes; however, they were not able to successfully adapt. Thus, corroborating our findings, the authors observed 

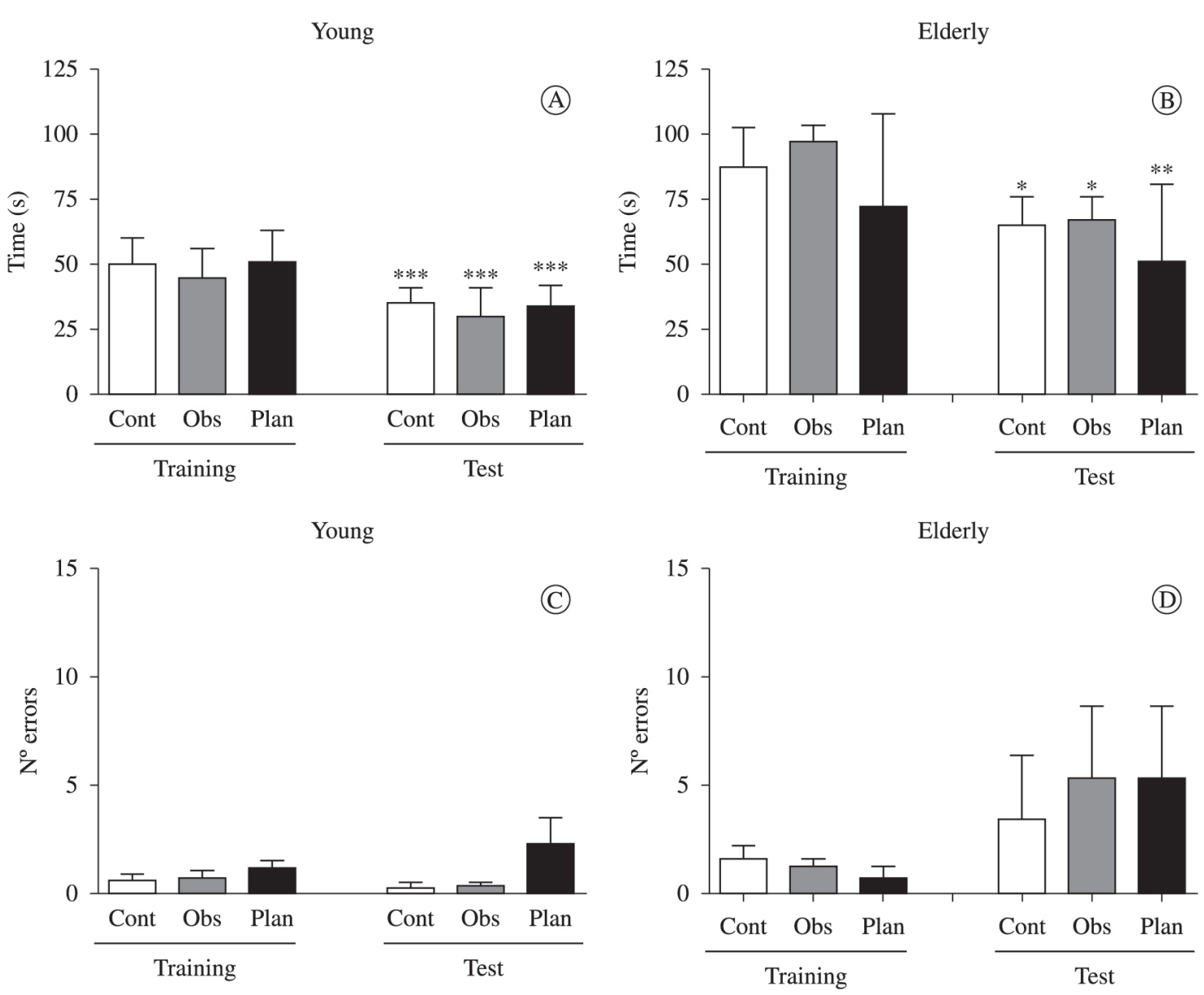

Figure 2. Comparison between time (figures A and B, median \pm interquartile range, Wilcoxon test) and the number of runtime errors (figures $\mathrm{C}$ and $\mathrm{D}$, mean \pm standard deviation, Student's $\mathrm{t}$ test for dependent samples) in the motor task when performed by young adults (figures A and C) and the elderly (Figures B and D) during training and testing ( $\mathrm{n}=15 /$ group, $* \mathrm{P}<0.05$, $* * \mathrm{P}<0.01$, $* * * \mathrm{P}<0.001$ compared to training the same subgroup).

that the elderly maintain their ability to learn but in a slower manner, i.e., the performance of the elderly decreases compared with young individuals due to aging. Diniz et al. ${ }^{34}$ also concluded that the more complex the task, the more difficult it is to perform.

The elderly seem to rely more on movement planning than on observation for the acquisition of a motor memory. Elderly individuals who performed motion planning (mental practice) during the training-test interval exhibited a significantly greater decrease in the time required to perform the task when compared with the other elderly groups (control and observation). Our findings support the notion of Tani et al. ${ }^{17}$ that when teaching a new task to older individuals, techniques different from those that are effective in young individuals can be effective for participants with a preserved cognitive and motor state. Taken together, our results suggest that for the elderly, the mental practice of a movement before its execution may favor performance.

Gomes et al. ${ }^{35}$ studied the effects of mental practice on the acquisition of motor skills in young individuals and observed a better performance in the groups performing physical practice combined with mental practice. That is, in this case, mental practice depends on physical practice to be effective during the learning of a motor skill. In our study, this association was not assessed; however, contrary to what was observed for the elderly, mental practice alone did not modify the learning ability of young subjects. Saimpont et al. ${ }^{36}$ emphasized that mental practice, in addition to being used to optimize motor function in sports and rehabilitation settings, can also benefit healthy elderly individuals facing age-related impairments in motor function. The use of mental practice is a safe and easy way to help preserve/ improve motor function in the elderly. 

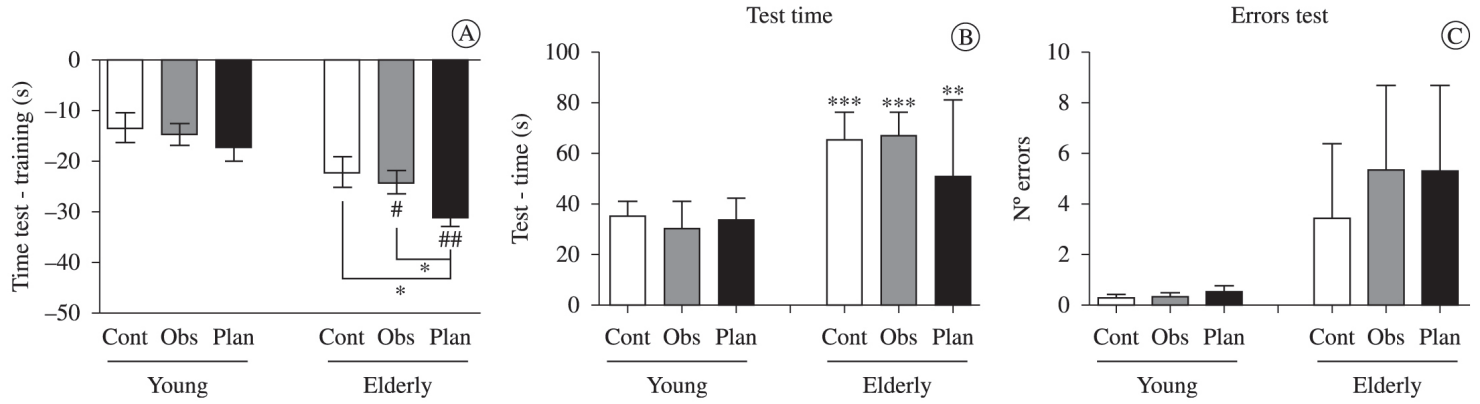

Figure 3. Comparison of the performances of young adults and the elderly on the motor task test showing the difference in the time required for the execution of the motor task in testing and training (figure A; median \pm standard error of the Mann-Whitney test; \# $\mathrm{P}<0.05$, \# \# $\mathrm{P}<0.01$ compared with the same young subgroup, ${ }^{*} \mathrm{P}<0.05$ compared to the control elderly subgroup); execution time (Figure $\mathrm{B}$, median \pm interquartile range test; Mann-Whitney test, ${ }^{* *} \mathrm{P}<0.01$ compared to the youth of the same subgroup; $* * * \mathrm{P}<0.001$ compared to the same young subgroup) and the number of errors (Figure $\mathrm{C}$, mean \pm standard deviation, $\mathrm{t}$-test of independent samples) ( $\mathrm{n}=15 / \mathrm{group}$ ).
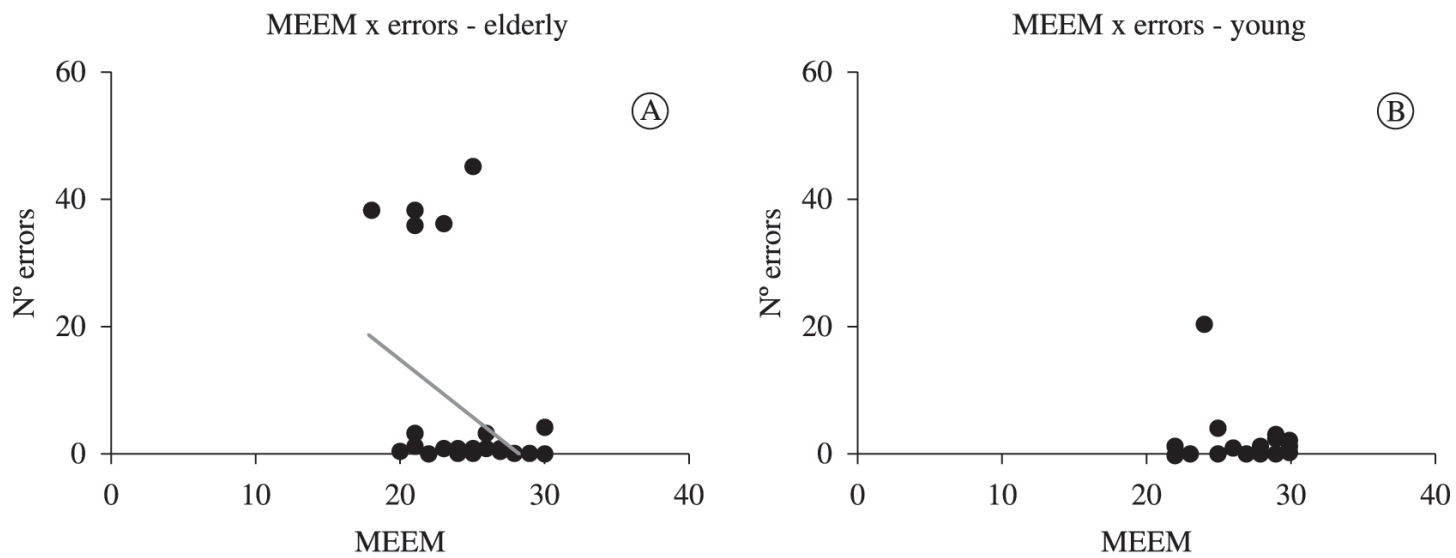

MEEM x time - elderly
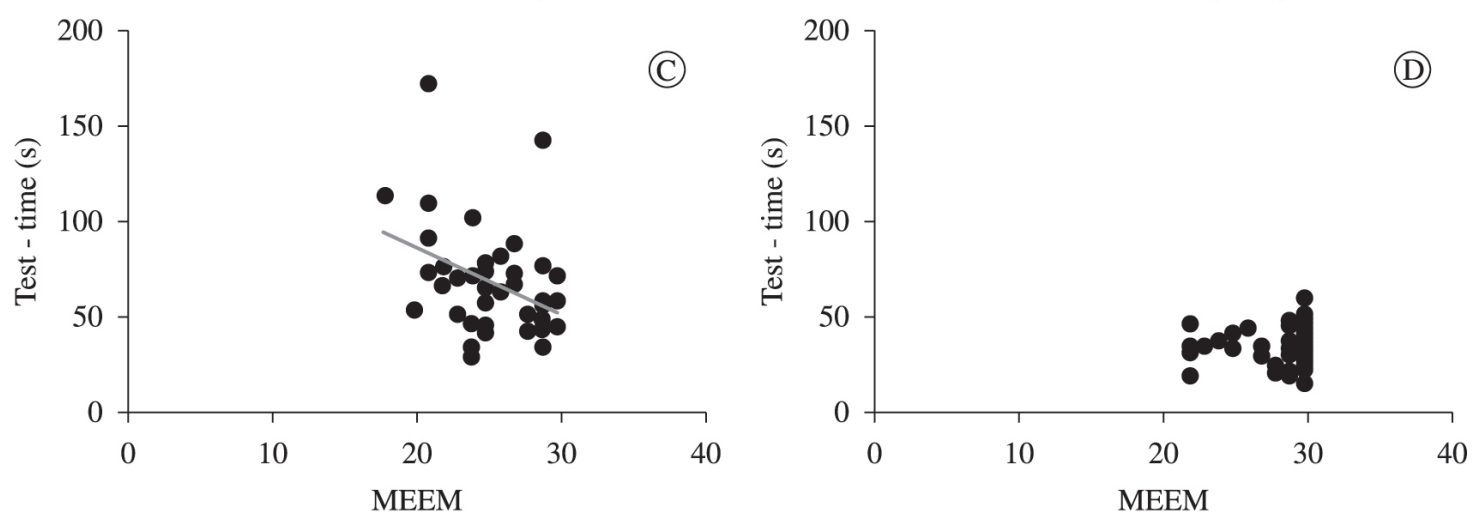

Figure 4. Correlation between cognitive function and motor performance in the execution of movements by elderly subjects (A, C) and young adults (B, D).

Movement observation did not have the same effect as mental practice on the learning of motor skills by the elderly. The main reason for this difference may be the fact that mental planning involves more attention to the task than observation and recruits neural pathways similar to those needed for the movement itself ${ }^{20}$. These results are extremely important when considering the choice of physical therapy techniques for intervention in elderly individuals. Mental stimulation has been shown to 
be an important tool when the goal is to promote learning or perfect a skill ${ }^{37}$, and thus, it can optimize the recovery process of elderly patients.

Results from other studies have also indicated the need to consider the differences in the motor learning of young individuals and elderly. Boyd et al. ${ }^{38}$ sought to identify motor, spatial and temporal characteristics that could affect the motor learning process and to determine whether age directly interferes with motor learning. Their results suggest that a decline in motor learning occurs due to old age, which should be considered in motor rehabilitation of the elderly. Teixeira ${ }^{39}$ compared the performances of different age groups, from young adults to the elderly, on motor tasks requiring distinct sensorimotor functions and concluded that there was no single pattern of performance decline. Moreover, the author found that the performance profile for each motor task seems to have particular characteristics throughout the aging process, with a moderate increase in reaction time from 20 to 60 years old and poorer performance in tasks that require speed from 20 to 40 years old. The author also emphasizes that elderly individuals showed improved performance on tasks practiced regularly, while young individuals usually have an advantage in non-routine tasks.

The present study showed that for elderly individuals, there is a relationship between cognitive function and motor performance in the execution of a sequence of digital movements. Despite the preservation of cognitive function in the subjects, ensuring the absence of dementia, the better the cognitive function, the better the motor learning. In young adults, the impact of cognition on motor learning was not significant because these individuals did not show any age-related cognitive deficits, with scores close to the maximum value in the evaluation of this function.

It is important to consider that diseases associated with aging are present in much of the elderly population and that these diseases may exacerbate the sensory and motor deterioration resulting from the natural aging process. Dementias are examples of these diseases, and they are characterized by a decline in cognitive function that leads to a significant impairment in performing daily activities. Dementias affect approximately $5 \%$ of the population more than 65 years old, and this frequency can reach $20 \%$ to $25 \%$ of the population more than 80 years old ${ }^{26}$. Therefore, because motor memory correlates with cognitive function, it is important that cognitive deficits are identified early in the elderly to ensure that the individuals maintain their autonomy, self-care and independence during the aging process.
Our results suggest that mental practice can positively influence motor learning and memory in the elderly, allowing better motor performance in individuals of this age group. A correlation between cognitive function and motor performance of the elderly was also observed.

The results in the present study may contribute to clinical practice in treating the elderly, allowing the identification of strategies that can facilitate motor learning and rehabilitation in this population. Given that aging leads to changes that may contribute to psychomotor limitations and reduced autonomy and skills, it is important that healthcare professionals, including physical therapists, study and assess, in the context of clinical practice, not only musculoskeletal capacity but also the cognitive functions of the elderly. When working with healthy elderly individuals or elderly with different levels of deficits, either cognitive or motor, these considerations should be taken into account when planning the rehabilitation program. Every activity must be learned with slow and controlled movements and easy to understand instructions, and healthcare professionals must respect the time needed by the elderly to learn and adjust their movement. Thus, the intervention will enable the most effective treatment for the patient.

\section{References}

1. Karuka AH, Silva JAMG, Navega MT. Analysis of agreement of assessment tools of body balance in the elderly. Rev Bras Fisioter. 2011;15(6):460-6. PMid:22218711. http://dx.doi.org/10.1590/S1413-35552011000600006

2. Lunenfeld B, Stratton P. The clinical consequences of an ageing world and preventive strategies. Best Pract Res Clin Obstet Gynaecol. 2013;27(5):643-59. PMid:23541823. http://dx.doi.org/10.1016/j.bpobgyn.2013.02.005

3. Bishop NA, Lu T, Yankner BA. Neural mechanisms of ageing and cognitive decline. Nature. 2010;464:529-535. PMid:20336135 PMCid:PMC2927852. http://dx.doi. org/10.1038/nature08983

4. Seidler RD. Differential effects of age on sequence learning and sensorimotor adaptation. Differential effects of age on sequence learning and sensorimotor adaptation. Brain Res Bull. 2006;70:337-46. PMid:17027769. http:// dx.doi.org/10.1016/j.brainresbull.2006.06.008

5. Degardin A, Devos D, Cassim F, Bourriez J-L, Defebvre L, Derambure P, et al. Deficit of sensorimotor integration in normal aging. Neurosci Lett. 2011;498:208-12. PMid:21600958. http://dx.doi.org/10.1016/j. neulet.2011.05.010

6. Zibetti MR, Gindri G, Pawlowski J, Salles JF, Parente MAMP, Bandeira DR, et al. Estudo comparativo de funções neuropsicológicas entre grupos etários de 21 a 90 anos. Revista Neuropsicologia Latinoamericana. 2010;2(1):55-67. 
7. Engvig A, Fjell AM, Westlye LT, Moberget T, Sundseth $\mathrm{O}$, Larsen VA, et al. Effects of memory training on cortical thickness in the elderly. NeuroImage. 2010;52:16671676. PMid:20580844. http://dx.doi.org/10.1016/j. neuroimage.2010.05.041

8. Chen KHM, Chuah LYM, Sim SKY, Chee MWL. Hippocampal region-specific contributions to memory performance in normal elderly. Brain Cogn. 2010;72:4007. PMid:20044193. http://dx.doi.org/10.1016/j. bandc.2009.11.007

9. Paulo DLV, Yassuda MS. Queixas de memória de idosos e sua relação com escolaridade, desempenho cognitivo e sintomas de depressão e ansiedade. Rev Psiq Clín. 2010;37(1):23-6. http://dx.doi.org/10.1590/ S0101-60832010000100005

10. Carvalho FCR, Neri AL, Yassuda MS. Treino de Memória Episódica com Ênfase em Categorização para Idosos sem Demência e Depressão. Psicol. Reflex. Crit. 2010;23(2):317-23. http://dx.doi.org/10.1590/ S0102-79722010000200014

11. Abel T, Lattal KM. Molecular mechanisms of memory acquisition, consolidation and retrieval. Curr Opin Neurobiol. 2001;11:180-7. http://dx.doi.org/10.1016/ S0959-4388(00)00194-X

12. Bureau G, Carrier M, Lebel M, Cyr M. Intrastriatal inhibition of extracellular signal-regulated kinases impaired the consolidation phase of motor skill learning. Neurobiol Learn Mem. 2010;9:107-15. PMid:20447478. http://dx.doi.org/10.1016/j.nlm.2010.04.008

13. Verwey WB. Diminished motor skill development in elderly: indications for limited motor chunk use. Acta Psychol. 2010;134:206-14. PMid:20189547. http://dx.doi. org/10.1016/j.actpsy.2010.02.001

14. Meaney K, Griffin K, Hart M. The effect of model similarity on girls' motor performance. J Teaching Phys Ed. 2005;24:165-78.

15. Ugrinowitsch H, Benda RN. Contribuições da Aprendizagem Motora: A prática na intervenção em Educação Física. Rev Bras Educ Fís Esporte. 2011;25:2535. http://dx.doi.org/10.1590/S1807-55092011000500004

16. Tonello MGM, Pellegrini AM. A utilização da demonstração para a aprendizagem de habilidades motoras em aulas de Educação Física. Rev Paul Educ Fís. 1998;12(2):107-14.

17. Tani G, Bruzi AT, Bastos FH, Chiviacowsky S. O estudo da demonstração em aprendizagem motora: estado da arte, desafios e perspectivas. Rev Bras Cineantropom Desempenho Hum. 2011;13(5):392-403. http://dx.doi. org/10.5007/1980-0037.2011v13n5p392

18. Dias VK, Duarte PSF. Idoso: níveis de coordenação motora sob a prática de atividade física generalizada. Efdeportes. 2005;89(10):23-33.

19. Fonseca FS, Siqueira MB, Bruzi AT, Fialho JV, Ugrinowitsch H, Benda RN. Demonstração e prática mental na aquisição de habilidades motoras. Rev Motricidade. 2008;4(2):62-67.

20. Skoura X, Papaxanthis C, Vinter A, Pozzo T. Mentally represented motor actions in normal aging I. Age effects on the temporal features of overt and covert execution of actions. Behav Brain Res. 2005;165(2):22939. PMid:16165229. http://dx.doi.org/10.1016/j. bbr.2005.07.023
21. Rossi ALS, Pereira VS, Driusso P, Rebelatto JR, Ricci NA. Profile of the elderly in physical therapy and its relation to functional disability. Braz J Phys Ther. 2013;17(1):77-85. PMid:23175439. http://dx.doi. org/10.1590/S1413-35552012005000060

22. Folstein MF, Folstein SE, McHugh PR. "Mini-Mental State": a pratical method for grading the cognitive state of patients for the cliniciam. J Psychiatr Res. 1975;12(3):18998. http://dx.doi.org/10.1016/0022-3956(75)90026-6

23. Brucki SMD, Nitrini R, Caramelli P, Bertolucci PHF, Okamoto IH. Sugestões para o uso do mini-exame do estado mental no Brasil. Arq Neuropsiquiatr 2003;61(3B):777-781. PMid:14595482. http://dx.doi.org/10.1590/ S0004-282X2003000500014

24. Oldfield RC. The assessment and analysis of handedness: the edinburgh inventory. Neuropsychologia. 1971;9(1):97113. http://dx.doi.org/10.1016/0028-3932(71)90067-4

25. Ungerleider LG, Doyon J, Karni A. Imaging brain plasticity during motor skill learning. Neurobiol Learn Mem. 2002;78(3):553-64. PMid:12559834. http://dx.doi. org/10.1006/nlme.2002.4091

26. Albouy G, Sterpenich V, Vandewalle G, Darsaud A, Gais S, Rauchs G, et al. Neural correlates of performance variability during motor sequence acquisition. NeuroImage. 2012;60(1):324-331. PMid:22227134. http:// dx.doi.org/10.1016/j.neuroimage.2011.12.049

27. Macêdo AML, Cerchiari EAN, Alvarenga MRM, Faccenda O, Oliveira MAC. Avaliação funcional de idosos com déficit cognitivo. Acta Paul Enferm. 2012;25(3):35863. http://dx.doi.org/10.1590/S0103-21002012000300007

28. Zeamer A, Decamp E, Clark K, Schneider JS. Attention, executive functioning and memory in normal aged rhesus monkeys. Behav Brain Res. 2011;219(1)23-30. PMid:21168445 PMCid:PMC3062645. http://dx.doi. org/10.1016/j.bbr.2010.12.021

29. Costarella M, Monteleone L, Steindler R, Zuccaro SM Decline of physical and cognitive conditions in the elderly measured through the functional reach test and themini-mental state examination. Arch Gerontol Geriatr. 2010;50(3):332-37. PMid:19545918. http://dx.doi. org/10.1016/j.archger.2009.05.013

30. Mozolic JL, Hayasaka S, Laurienti PJ. A cognitive training intervention increases resting cerebral blood flow in healthy older adults. Front Hum Neurosci. 2010;4(16):1-10.

31. Martins AB, Dascal JB, Bruzi AT, Caldeira MD, Turetta C. Interferência de tarefas motoras com diferentes demandas de processamento sobre o tempo de reação de idosos e adultos jovens. Rev Bras Ciênc Esporte. 2010;1(2):127-34.

32. Fraser SA, Li KZ, Penhune VB. Dual-task performance reveals increased involvement of executive control in fine motor sequencing in healthy aging. J Gerontol B Psychol Sci Soc Sci. 2010;65(5):526-35. PMid:20478900. http:// dx.doi.org/10.1093/geronb/gbq036

33. Toledo DR, Barela JA. Sensory and motor differences between young and older adults: somatosensory contribution to postural control. Rev Bras Fisioter. 2010;14(3):267-75. http://dx.doi.org/10.1590/ S1413-35552010000300004

34. Diniz AB, Basso L, Hashiguchi D, Beltrão NB, Correia ERFG, Oliveira DS, et al. Aprendizagem de uma habilidade 
motora seriada em diferentes estágios de desenvolvimento. Rev Bras Educ Fís Esporte. 2012;26(1):119-28. http:// dx.doi.org/10.1590/S1807-55092012000100012

35. Gomes TVB, Ugrinowitsch H, Marinho NFS, Benda RN. Efeitos da prática mental na aquisição de habilidades motoras em sujeitos novatos. Rev Bras Educ Fís Esporte. 2012;26(3):511-21. http://dx.doi.org/10.1590/ S1807-55092012000300016

36. Saimpont A, Malouin F, Tousignant B, Jackson PL. Motor imagery and aging. J Mot Behav. 2013;45(1):2128. PMid:23394362. http://dx.doi.org/10.1080/0022289 5.2012 .740098

37. Barato G, Fernandes T, Pacheco M, Bastos VH, Machado $\mathrm{S}$, Mello MP, et al. Plasticidade cortical e técnicas de fisioterapia neurológica na ótica da neuroimagem. Rev Neurocienc. 2009;17(4):342-8.

38. Boyd LA, Vidoni ED, Siengsukon CF. Multidimensional motor sequence learning is impaired in older but not younger or middle-aged adults. Phys Ther. 2008;88(3):351-62. PMid:18096651. http://dx.doi.org/10.2522/ptj.20070131

39. Teixeira LA. Declínio de desempenho motor no envelhecimento é específico à tarefa. Rev Bras Med Esporte. 2006;12(6):351-5. http://dx.doi.org/10.1590/ S1517-86922006000600010

\section{Correspondence}

\section{Pâmela B. Mello-Carpes}

Universidade Federal do Pampa

Laboratório de Estresse, Memória e Comportamento BR 472, km 592

CP 118, CEP 97500-970, Uruguaiana, RS, Brasil

e-mail: pamelacarpes@unipampa.edu.br 